\title{
In-Hospital Outcome of Compromised Small Side Branch after Percutaneous Coronary Intervention
}

\author{
MM Alam, M Ali, MSR Patwary, SMA Romel , MS Kabir, KU Ahmed, KK Sen, AR Khan, MA Razzaque \\ Department of Cardiology, National Institute of Cardiovascular Disease (NICVD),Dhaka
}

Key words:

Percutaneous

coronary

intervention,

Side branch, In-

hospital

outcome.

\begin{abstract}
Background: Side branch occlusion is a well known complication of percutaneous coronary intervention. Although occlusion of small side branches is well tolerated, occlusion of larger side branches may cause more serious complications. After PCI the incidence of complications in patients with compromised side branches smaller than $2 \mathrm{~mm}$ is small. Compromising side branches larger than $2 \mathrm{~mm}$ can be accompanied by clinical outcomes as non Q-wave MI. This study was undertaken to assess the in-hospital outcomes of compromised small $(<2 \mathrm{~mm})$ side branch after percutaneous coronary intervention.
\end{abstract}

Methods: This cross sectional analytical study was carried out in the department of cardiology, National Institute of Cardiovascular Diseases, Dhaka during the period of September 2011 to June 2012. A total of 100 consecutive patients with coronary artery disease who underwent elective PCI were included in the study. Study patients were divided into two groups on the basis of presence of compromised small $(<2$ $\mathrm{mm}$ ) side branch. In Group- I, small $(<2 \mathrm{~mm})$ side branch were compromised after PCI and in Group- II, side branches were patent after PCI, with 50 patients in each group. In-hospital outcome were evaluated in both groups.

Result: There were no significant differences of the baseline clinical demographics between two groups. Post PCI angina was higher in group I than group II (10.0\% vs. 9.0\%). Non ST elevation myocardial infarction and significant arrhythmia was identical in both groups (2.0\% vs. $2.0 \%$ ) but hypotension was more in group II than group I (4.0\% vs. $2.0 \%)$. The findings were statistically insignificant between the study groups. There was no mortality, emergency CABG within 24 hours, ST elevation myocardial infarction, cardiogenic shock or acute left ventricular failure during their hospital course in either group.

Conclusion: The present study concluded that compromised small $(<2 \mathrm{~mm})$ side branch after percutaneous coronary intervention was not associated with adverse in-hospital outcome.

(Cardiovasc. j. 2014; 7(1): 11-16)

\section{Introduction:}

Percutaneous transluminal coronary angioplasty with stenting has now become the preferred treatment of coronary artery disease for interventional cardiologists. ${ }^{1}$ The risk of side branch occlusion is a well known complication of coronary intervention and has been reported to be about 12-41 percent. ${ }^{2,3}$ This complication is related to either plaque shifting effect, thrombus formation, dissection, spasm, plaque embolization, or side-branch ostial compromise by stent material. ${ }^{4,5}$

Although occlusion of small side branches is well tolerated, occlusion of larger side branches may cause more serious complications. ${ }^{6,7}$ Acute small side branch occlusion is not associated with MACE (death, Q- wave MI and need for repeat target vessel revascularization) during hospital stay and at follow-up. ${ }^{8,9,10}$ Compromising side branches larger than $2 \mathrm{~mm}$ can be accompanied by clinical outcomes as non Q-wave MI. ${ }^{11}$ The purpose of this study was to assess the in-hospital outcomes of compromised small $(<2 \mathrm{~mm})$ side branch after percutaneous coronary intervention.

\section{Materials and methods:}

This cross sectional analytical study was carried out in the department of cardiology, National Institute of Cardiovascular Diseases, Dhaka during the period of September 2011 to June 2012.

The main objective of the study was to assess in- hospital outcome of patients with

Address of correspondence: Dr. Md. Mahbub Alam, Department of Cardiology, National Institute of Cardiovascular Diseases, Dhaka, Bangladesh. e mail: jibanmahbub@yahoo.com 
compromised small side branch after percutaneous coronary intervention. A total of 100 consecutive patients with coronary artery disease who were undergone elective PCI were included in the study. Study patients were divided into two groups on the basis compromised small $(<2 \mathrm{~mm})$ side branch. In Group- I, small $(<2 \mathrm{~mm})$ side branch were compromised after PCI and in Group- II, side branches were patent after PCI, with 50 patients in each group. History of acute myocardial infarction within 72 hours of intervention, all emergency percutaneous coronary intervention, angiographic evidence of thrombus within the target lesion, poor distal run-off, and presence of total occlusion, left main or three- vessel disease, side branch dilatation or side branch protection by guidewire during the angioplasty procedure, side branches with a luminal diameter less than $1 \mathrm{~mm}$ and more than $2 \mathrm{~mm}$, side branches with TIMI 2 flow or less before percutaneous coronary intervention, severe left ventricular systolic dysfunction, patient with severe co morbidity (Stroke, chronic obstructive pulmonary disease, chronic kidney disease), target lesion revascularization, target vessel revascularization were excluded from the study. Study protocol was approved by the Ethical Review Committee of NICVD.

Coronary angioplasty was performed using the standard percutaneous techniques with the femoral artery approach, and the standard methods were used for stent implantation. Side branch was considered compromised when occlusion of the side branch with TIMI 2 flow or less in the side branch. ${ }^{11}$.

All the patients evaluated clinically for adverse in-hospital outcome and routinely underwent pre- and postintervention 12-lead electrocardiography \& echocardiography. The levels of creatine kinase-MB (CK-MB) enzymes and were measured from blood samples obtained before the PCI and $12-18$ hours after the PCI.

\section{Adverse in-hospital outcome:}

Following parameters were assessed to estimate the adverse in hospital outcome-

- Post procedural angina: Occurrence of post procedural angina was followed up by subjective evidence of chest pain and by doing ECG, echocardiography.

- Heart failure: Occurrence of heart failure was followed up clinically by Killip class and by doing echocardiography.

- Myocardial infarction: Occurrence of myocardial infarction was followed up by subjective evidence of continuous or recurrent chest pain, protracted elevation of CK-MB level, ECG and echocardiography.

- Hypotension

- Significant arrhythmia: Follow up ECG was done 8 hourly. Bedside monitor parameters and follow up records were noted.

- Cardiogenic shock: Follow up was done for features of shock.

- Emergency CABG within 24 hours.

- Death

\section{Statistical Analysis}

The numerical data obtained from the study were analyzed and significance of differences were estimated by using statistical methods. Computer based SPSS (Statistical Package for Social Science) was used. Data were expressed in percentage, frequencies, means and standard deviation as applicable and were analysed by ChiSquare test, Fisher's exact test, Students' t test and multivariate logistic regression analysis as applicable. $\mathrm{P}$ value of less than 0.05 was considered as significant.

\section{Results:}

There were no significant differences between those with and without side branch compromise in terms of bseline clinical and demographic characteristics (Table I and Table II).

Table III showed that CK-MB level of group I and groups II. The mean increase CK-MB level after PCI was higher in group II (12.60 $\pm 7.60 \mathrm{U} /$ L) than group I $(11.00 \pm 5.72 \mathrm{U} / \mathrm{L})$. The mean differences of CK-MB level in both study groups were not statistically significant $(p>0.05)$.

Table IV shows the distribution of the study patients by in-hospital outcome. Five $(10.0 \%)$ patients developed angina after PCI in group I and four $(9.0 \%)$ developed angina after PCI in group II. One (2.0\%) patient developed non ST 
Table-I

Risk factors distribution of the study population ( $n=100)$

\begin{tabular}{lcccccc}
\hline Risk Factors & \multicolumn{2}{c}{ Group I $(\mathrm{n}=50)$} & & \multicolumn{2}{c}{ Group II (n =50) } & $\mathrm{p}$ value \\
\cline { 2 - 3 } & Number & $\%$ & & Number & $\%$ & \\
\hline Smoking & 18 & 36.0 & & 16 & 32.0 & $0.67^{\mathrm{ns}}$ \\
Hypertension & 16 & 32.0 & & 13 & 26.0 & $0.51^{\mathrm{ns}}$ \\
Diabetes mellitus & 16 & 32.0 & & 19 & 38.0 & $0.52^{\text {ns }}$ \\
Dyslipidemia & 12 & 24.0 & & 16 & 32.0 & $0.37^{\mathrm{ns}}$ \\
Family H/O premature CAD & 8 & 16.0 & & 6 & 12.0 & $0.56^{\mathrm{ns}}$ \\
\hline
\end{tabular}

Table-II

Clinical parameters of study population $(n=100)$

\begin{tabular}{lccc}
\hline Clinical parameter & Group I & Group II & p vale \\
& Mean \pm SD & Mean \pm SD & \\
\hline Age & $54.82 \pm 9.76$ & $51.46 \pm 8.31$ & $0.06^{\text {ns }}$ \\
BMI & $24.67 \pm 1.73$ & $23.58 \pm 1.72$ & $0.68^{\text {ns }}$ \\
Pulse/min & $79.2 \pm 7.3$ & $79.2 \pm 7.9$ & $0.97^{\text {ns }}$ \\
Systolic BP(mmHg) & $117.7 \pm 10.6$ & $112.9 \pm 11.2$ & $0.03^{\text {s }}$ \\
Diastolic BP(mmHg) & $72.4 \pm 6.7$ & $72.1 \pm 5.2$ & $0.80^{\text {ns }}$ \\
LVEF $(\%)$ & $53.8 \pm 5.4$ & $54.2 \pm 5.1$ & $0.71^{\text {ns }}$ \\
\hline
\end{tabular}

Table-III

Comparison of pre and post PCI CK-MB changes of the study population ( $n=100)$

\begin{tabular}{lccl}
\hline CK-MB & $\begin{array}{c}\text { Group I }(\mathrm{n}=50) \\
\text { Mean } \pm \text { SD }\end{array}$ & $\begin{array}{c}\text { Group II }(\mathrm{n}=50) \\
\text { Mean } \pm \text { SD }\end{array}$ & p value \\
\hline Pre PCI (U/L) & $22.82 \pm 6.53$ & $21.28 \pm 2.35$ & $0.12^{\text {ns }}$ \\
Post PCI (U/L) & $33.82 \pm 7.52$ & $33.88 \pm 8.02$ & $0.96^{\text {ns }}$ \\
Mean increase (U/L) & $11.00 \pm 5.72$ & $12.60 \pm 7.60$ & $0.24^{\text {ns }}$ \\
\hline
\end{tabular}

elevation myocardial infarction in group I and one $(2.0 \%)$ patient developed non ST elevation myocardial infarction in group II. Two (4.0\%) patients developed hypotension in group II but one $(2.0 \%)$ patient developed hypotension in group I. One $(2.0 \%)$ patient in each group developed significant arrhythmia (in group I it was atrial fibrillation and in group II it was multiple ventricular ectopics). No one developed ST elevation myocardial infarction, cardiogenic shock or heart failure. There was no mortality or emergency CABG within 24 hours. All outcomes were found almost identical with no statistical significant difference $(p>0.05)$.
It was observed that the post PCI hospital stay status was almost identical in group I and group II ( $p>0.05)$ which was about 3 days in both groups (Table V).

The binary logistic regression analysis (Table VI) showed that advance age, female gender, diabetes mellitus, acute myocardial infarction were the independent predictors for developing adverse in-hospital outcome with ORs being 2.63, 2.26, 3.93 and 1.21. Compromised small side branch was found not an independent predictors for developing adverse in-hospital outcome $(\mathrm{p}>0.05)$. 
Table-IV

Comparison of patients by in-hospital outcome ( $n=100)$

\begin{tabular}{lccccc}
\hline In-hospital outcome & \multicolumn{2}{c}{ Group I $(\mathrm{n}=50)$} & \multicolumn{2}{c}{ Group II $(\mathrm{n}=50)$} & $\mathrm{p}$ value \\
& Number & $\%$ & Number & $\%$ & \\
\hline Angina (Chest pain) & 5 & 10.0 & 4 & 9.0 & $0.73^{\text {ns }}$ \\
NSTEMI & 1 & 2.0 & 1 & 2.0 & $1.00^{\text {ns }}$ \\
Hypotension & 1 & 2.0 & 2 & 4.00 & $0.73^{\text {ns }}$ \\
Arrhythmias & 1 & 2.0 & 1 & 2.0 & $1.00^{\text {ns }}$ \\
\hline
\end{tabular}

Table-V

Comparison of post PCI hospital stay between groups $(n=100)$

\begin{tabular}{lccc}
\hline Hospital stay (Day) & Group I $(\mathrm{n}=50)$ & Group II $(\mathrm{n}=50)$ & p value \\
& Mean \pm SD & Mean \pm SD & \\
\hline DayRange (Min-Max) & $2.90 \pm 0.70(2-5)$ & $2.82 \pm 0.62(2-5)$ & $0.55^{\text {ns }}$ \\
\hline
\end{tabular}

Table-VI

Binary Logistic regression analysis of factors related to adverse in-hospital outcome

\begin{tabular}{lcccc}
\hline Variables of interest & Univariate analysis & \multicolumn{3}{c}{ Multivariate analysis } \\
\cline { 3 - 5 } & $\mathrm{p}$ value & OR & $95 \%$ CI of OR & $\mathrm{p}$ value \\
\hline Advance age $(>60$ years $)$ & $0.001^{\mathrm{s}}$ & 2.63 & $1.534-6.264$ & 0.002 \\
Female gender & $0.02^{\mathrm{s}}$ & 2.26 & $0.776-5.126$ & 0.04 \\
Diabetes mellitus & $0.01^{\mathrm{s}}$ & 3.93 & $1.290-11.995$ & 0.02 \\
Double Vessel disease & $0.12^{\mathrm{ns}}$ & 2.36 & $0.797-6.990$ & 0.16 \\
Acute MI & $0.03^{\mathrm{s}}$ & 1.21 & $0.205-1.926$ & 0.04 \\
Type of C lesion & $0.24^{\mathrm{ns}}$ & 1.92 & $0.641-5.773$ & 0.44 \\
Compromised small side branch & $0.28^{\mathrm{ns}}$ & 1.83 & $0.611-5.502$ & 0.39 \\
\hline
\end{tabular}

\section{Discussion:}

The mean $( \pm \mathrm{SD})$ age of the patients was $54.82 \pm$ 9.76 years and $51.46 \pm 8.31$ years in group I and group II respectively, no significant difference was found between two groups. Most of the patients were in 5 th decade in both groups.

In this study male sex predominated in both groups. Male female ratio was 11.5:1 among the study population. No significant $(p>0.05)$ difference was found regarding sex distribution between two groups. In our country percutaneous coronary intervention (PCI) rates in females are less then male because of economic dependency.

In this study baseline clinical parameter, ischemic heart disease status, pre PCI ECG findings and most of the angiographic and procedural characteristics were similar between two groups and statistically insignificant $(\mathrm{p}>$ 0.05).

The mean left ventricular ejection fraction was $53.8 \pm 5.4 \%$ and $54.2 \pm 5.1 \%$ in group I and group II respectively. In this study we excluded patients with severe left ventricular dysfunction. Patients with severe left ventricular dysfunction had higher risk of developing adverse in-hospital outcome. ${ }^{12}$

In this study it was observed that CK-MB level increased in both groups after PCI. The mean increase CK-MB level after PCI was higher in group II than group I $(12.60 \pm 7.60 \mathrm{U} / \mathrm{L}$ vs. $11.00 \pm 5.72 \mathrm{U} / \mathrm{L})$. The findings were not statistically significant between the study groups $(p>0.05)$. Lee, et al. ${ }^{13}$ found in their study that the peak values for the post PCI CK-MB were 
13.5 U/L and 15.6 U/L in the group I and group II respectively which were consistent with our study.

In-hospital outcomes after PCI in both groups were recorded in this study. It was found that post PCI angina was higher in group I than group II (10.0\% vs. $9.0 \%)$. Non ST elevation myocardial infarction and significant arrhythmia was identical in both groups $(2.0 \%$ vs. $2.0 \%)$ but hypotension was more in group II than group I $(4.0 \%$ vs. $2.0 \%))$. In this study no one developed ST elevation myocardial infarction, cardiogenic shock or acute left ventricular failure during their hospital course in either group. There was no mortality or emergency CABG within 24 hours during the in-hospital period both in group I and group II. These findings were consistent with study done by Dehghani et al, ${ }^{14}$ Lee et al, ${ }^{13}$ Ghayemain et al, ${ }^{11}$ Cho et $\mathrm{al}^{7}$ and Nozari et al. ${ }^{15}$

Dehghani et al. ${ }^{14}$ reported in their study that during hospital stay the incidence of major adverse cardiac events (MACE) comprising death, need for target vessel revascularization, and Q-wave MI was almost similar in the patients with and in those without acute side branch occlusion. Lee et al. ${ }^{13}$ found that there were no clinical in-hospital events for either group. Ghayemain et al. ${ }^{11}$ demonstrated that the incidence of complications in patients with compromising side branches smaller than $2 \mathrm{~mm}$ is small, compromising side branches larger than $2 \mathrm{~mm}$ can be accompanied by clinical outcomes as non Q-wave MI. Cho, et al. ${ }^{7}$ reported in their study that there was no emergency bypass surgery or deaths during the acute hospitalization in patients with side branch occlusion (SBO). Nozari et al. ${ }^{15}$ found in their study that side branch compromise $(<2 \mathrm{~mm})$ was not associated with adverse clinical outcomes.

The mean hospital stay after PCI was $2.9 \pm 0.70$ days and $2.82 \pm 0.62$ days in group I and group II respectively with no statistical difference $(p>0.05)$. Dehghani et al. ${ }^{14}$ reported in their study that the length of hospital stay in the patients with acute side branch occlusion was $48 \pm 12$ hours and $48 \pm 5$ hours in the patients without acute side branch occlusion. These findings were consistent with our study.
In this study by the multivariate logistic regression analysis it was observed that advance age ( $>60$ years), female gender, diabetes mellitus and acute MI were independent predictors for developing adverse in-hospital outcome with ORs being $2.63,2.26,3.93$ and $1.21(\mathrm{p}<0.05)$. But it was found that compromised small $(<2 \mathrm{~mm})$ side branch, double vessel disease and type $\mathrm{C}$ lesion were not independent predictors for developing adverse in-hospital outcome ( $p>0.05)$.

\section{Conclusion:}

The present study concluded that compromised small $(<2 \mathrm{~mm})$ side branch after percutaneous coronary intervention was not associated with adverse in-hospital outcome. This study also concluded that in-hospital outcomes were similar both in patients with compromised small $(<2 \mathrm{~mm})$ side branch and patients with patent side branch after percutaneous coronary intervention.

\section{Study limitation}

In this study we included only stable patients. We excluded patient with left main disease, triple vessel disease and patients with severe left ventricular dysfunction. In case of severe left ventricular dysfunction even small side compromise may associated with adverse inhospital outcome. Number of study population was small. It was a single centered non randomized study. Follow up period was short.

\section{Conflict of Interest - None.}

\section{References:}

1. Butany J, Carmichael K, Leong SW, et al. Coronary artery stents: identification and evaluation. J Clin Pathol 2005 ; 58:795-804.

2. Timurkayank T, Ciftci H, Ozdemir M, et al. Sidebranch occlusion after coronary stenting with or without ballon predilation: Direct versus conventional stenting. J Invasive Cardiol 2002; 14(9): 497-501.

3. Cervinka P, Foley DP, Sabate M, et al. Coronary bifurcation stenting using dedicated bifurcated stents. Catheter Cardio Inte 2000 ; 49:105-111.

4. Arora RR, Raymond RE, Dimas AP, et al. Side Branch Occlusion During Coronary Angioplasty: Incidence, Angiographic Characteristics, and Outcome. Catheter Cardio Diag $1989 ; 18: 210-212$.

5. Iniguez A, Macaya C, Alfonso F, et al. Early angiographic changes of side branches arising from a Palmaz-Schatz stented coronary segments: results and clinical implications. J Am Coll Cardiol 1994 ; 23 : 911-915. 
6. Aliabadi D, Tilli FV, Bowers TR, et al. Incidence and angiographic predictors of side branch occlusion following high-pressure intracoronary stenting. Am J Cardiol 1997 ; 80 : 994-997.

7. Cho GY, Lee CW, Hong M-K,et al. Effect of stent design on side branch occlusion after coronary stent plancement. Catheter Cardio Interv 2001 ; 52 :18-23.

8. Poerner TC, Kralev S, Voelker W, et al. Natural history of small and medium-sized side branches after coronary stent implantation. Am Heart J 2002; 143: 627-635.

9. Kralev S, Poerner TC, Basorth D, et al. Side branch occlusion after coronary stent implantation in patients presenting with ST-elevation myocardial infarction: Clinical impact and angiographic predictors. Am Heart $J$ 2006; 151: 153-157.

10. Mazur W, Grinstead C, Hakim AH, et al. Fate of side branches after intracoronary implantation of the Giantourco-Roubin flex-stent for acute or threatened closure after PTCA. Am J Cardiol 1994 ; 74 : 1207-1210.
11. Ghayemain A, Nozari Y, Safir M, et al. Predictors of side branch occlusion and its early complications after angioplasty in bifurcation lesions. Pak J Med Sci 2008; 24(3) : 430-435.

12. Sing M. Risk stratification in interventional cardiology. In: S.B. King and A.C. Young, Eds. Interventional cardiology. NewYork : Mc Graw-Hill ; 2007 : 598-604.

13. Lee DW, Ha JK, An SG, et al. Comparison of the Clinical and Angiographic Outcomes of Compromised Side Branches (Stent Jail) after Percutaneous Coronary Intervention between Sirolimus-Eluting Stents and Paclitaxel-Eluting Stents. Korean Circ J 2007 ; 37 : 630-634.

14. Dehghani M, Falsolaiman H, Mahmoodi Z. Angiographic Predictors and Clinical Outcome of Acute Side Branch Occlusion after Coronary Artery Stent Implantation. Iranian Heart Journal 2008 ; 9(3) : 18 -24.

15. Nozari Y, Gaemian A, Safir MA. Predictors of Side Branch Compromise and related early complications after percutaneous coronary intervention. Tehran University Medical Journal 2007 ; 65(3) : 30-35. 